\title{
Air jet Erosion Wear behavior of Al6061-SiC-Carbon fibre Hybrid Com- posite
}

\author{
C.S. Ramesh ${ }^{1, a}$, Shreeshail M. L. ${ }^{2, b}$, Harsha Gudi ${ }^{2, c}$ and Zulfiqar Khan ${ }^{3, d}$
}

${ }^{1}$ Mechanical Engineering, PES Institute of Technology, 100ft Ring Road, BSK III Stage, Bangalore560 085. Karnataka, India. And Visiting Professor, School of Design, Engineering and Computing, Bournemouth University, Dorset, UK.

${ }^{2}$ Mechanical Engineering, PES Institute of Technology, 100ft Ring Road, BSK III Stage, Bangalore560 085. Karnataka, India..

${ }^{3}$ School of Design, Engineering and Computing, Bournemouth University, Dorset, UK.

acsr_gce@yahoo.co.in, bshreeshailmlmech@yahoo.com, charsha.gudi@gmail.com, dZKhan@bournemouth.ac.uk

Keywords: Air Jet Erosion, Al6061, SiC, Hybrid composite.

\begin{abstract}
Currently, the focus in materials development is on processing of hybrid metal matrix composites (MMC's) in particular aluminum (Al) based owing to their flexibility in achieving tailor made properties. Till date, only processing, characterization of mechanical and adhesive wear behavior of various hybrid MMCs have received much attention. However, solid erosion wear of hybrid MMCs has not yet been reported. This assessment will further enlarge the range of applications of hybrid MMCs in particular for components in operation for military applications especially in desert areas. In the light of the above, the present paper discusses the air jet erosion behavior of developed Al6061-SiC-carbon fibre hybrid composite prepared by combination of powder metallurgy and casting process followed by hot extrusion at temperature of $550^{\circ} \mathrm{C}$ using extrusion ratio of 1:4. The solid sand erodent particle size used was $312 \mu \mathrm{m}$ while the operating pressure and velocity was maintained at $1.4 \mathrm{bar}$ and $30 \mathrm{~m} / \mathrm{sec}$ respectively. The adopted feed rate of the sand particles was 2.0 $\mathrm{g} / \mathrm{min}$ with standoff distance being $10 \mathrm{~mm}$. The sample size was $25 \mathrm{~mm}$ x $25 \mathrm{~mm}$ x $10 \mathrm{~mm}$. The effect of silicon carbide ( $\mathrm{SiC})$, Carbon fibre $\left(\mathrm{C}_{\mathrm{f}}\right)$, test duration and angle of impingement of the erodent on the erosion wear loss of the developed hybrid composite will be discussed at length.
\end{abstract}

\section{Introduction}

Metal matrix composites (MMC's) are presently the most preferred innovative materials due to their excellent strength, higher wear resistance, better thermal conductivity and low coefficient of thermal expansion. It has been nearly three decades, that these exotic materials are mainly processed by two well established techniques namely the powder and liquid metallurgy. Homogeneity in the distribution and high volume fractions of reinforcements in the matrix alloy are the characteristics features of the powder metallurgical processing technique. However, the liquid metallurgy processing technique possesses unique features such as mass production of large and complex shaped composite castings. A blend of the above two processes will positively bring out enhanced homogeneity, greater volume incorporation of reinforcements, leading to production of light weight large structures with improved mechanical and tribological properties of the composites [1]. It has been reported that increased content of hard reinforcement in the soft matrix alloy has resulted in effective decrease in wear rates of the composites [2]. Majority of the metal matrix composite materials systems studied are reinforced with ceramics possessing high hardness and strength either continuous in the form of fibre or discontinuous in the form of whisker, platelets or particulate reinforcements embedded in a ductile metallic matrix [3]. Most of the researchers have focused their attention on processing and characterization of mechanical and adhesive wear behavior of MMC's $[4,5,6]$. Currently MMC's are being explored as the candidate materials for components subjected 
to hard solid particle erosion. Meager information is available as regards the assessment of solid particle erosion wear of MMC's although researchers have reported on erosive wear behavior of polymer based composites [7,8]. Decrease in the angle of impact from $90^{\circ}$ to $20^{\circ}$ has resulted in significant increase in erosion wear loss and ductility [9]. The mass loss of the target material subjected to sand particle erosion tests is directly proportional to kinetic energy and is inversely to the hardness of the target material [10]. Metal matrix composites with silicon carbide as the reinforcement possesses the maximum erosion wear resistance its mass fraction ranging from 60 to $75 \mathrm{Wt} \%$ [11]. Interesting work on erosive wear of polymer based composites has been reported. Factors such as impingement angle, impact velocity, erodent size and amount of reinforcement are the major factors affecting the erosion rate of composites [12,8]. It has been reported that glass and carbon fibre reinforced composites do exhibit semi-ductile erosion characteristics with the peak erosion wear occurring at $60^{\circ}$ impingement angle $[12,13]$. Hybridization of the reinforcements with use of discontinuous fibres and hard particulates in processing of MMC's leads to improved hardness, strength and wear resistance. However, no information is available as regards the erosive wear of hybrid MMC's with hard particulate and discontinuous fibre reinforcements. In the light of the above, this work focuses on novel processing of hybrid MMC's and assessing its erosive wear behavior.

\section{Experimental Procedure}

A16061 the most accepted aerospace alloy was chosen as the matrix. Powders of Al6061and silicon carbide of particle size ranging from 25-35 $\mu \mathrm{m}$ and discontinuous carbon fibres of diameter ranging 8-10 $\mu \mathrm{m}$ were compacted using 100T hydraulic press. The powder-fibre compacts were of cylindrical shape of diameter $25 \mathrm{~mm}$ and height $30 \mathrm{~mm}$. The proportion of silicon carbide powder and carbon fibre in the composite mix was 40 and $10 \mathrm{Wt} \%$ respectively. These composite compacts were arranged in a circular array inside the cast iron mould in to which molten Al6061 alloy was poured. The pouring temperature was maintained at $710^{\circ} \mathrm{C}$. After casting, the developed composites were machined to cylindrical billet of diameter $70 \mathrm{~mm}$ and height $75 \mathrm{~mm}$ for hot extrusion. A 200T hydraulic press was used while adopting an extrusion ratio of 1:4 and an extrusion temperature of $520^{\circ} \mathrm{C}$. The hot extruded composite were subjected to dry air jet erosion wear tests.

An air jet erosion test machine was used to assess the erosion wear behavior of the developed hot extruded hybrid composite and the matrix alloy. The erodent used was sand particle of size $312 \mu \mathrm{m}$, while the operating pressure and velocity were maintained at $1.4 \mathrm{bar}$ and $30 \mathrm{~m} / \mathrm{sec}$ respectively. Table 1 reports the test conditions adopted during the air jet erosion studies.

Table 1. Air Jet Erosion Test Conditions.

\begin{tabular}{|c|l|l|}
\hline $\begin{array}{r}\text { S1 } \\
\text { no. }\end{array}$ & \multicolumn{2}{|c|}{ Test parameters } \\
\hline 1. & Erodent material & Silica sand \\
\hline 2. & Erodent size $[\mu \mathrm{m}]$ & 300 \\
\hline 3. & Particle velocity $[\mathrm{m} / \mathrm{s}]$ & 30 \\
\hline 4. & Erodent feed rate $[\mathrm{g} / \mathrm{m}]$ & 2 \\
\hline 5. & Impact angle $[$ degrees $]$ & $90,75,60$ and 45 \\
\hline 6. & Test temperature & Room temperature \\
\hline 7. & Test time $[$ minutes $]$ & 30 (in steps of 5$)$ \\
\hline 8. & Sample size $[\mathrm{mm}]$ & $25 \times 25 \times 8$ \\
\hline 9. & Nozzle inner diameter $[\mathrm{mm}]$ & 1.5 \\
\hline 10. & Standoff distance $[\mathrm{mm}]$ & 10 \\
\hline 11. & System pressure $[$ bar $]$ & 1.4 \\
\hline
\end{tabular}


Weight loss of the matrix alloy and the developed Al6061- 40wt $\%$ SiC- $10 \mathrm{wt} \% \mathrm{C}_{\mathrm{f}}$ composite before and after erosion wear tests were recorded using a precision micro balance of accuracy 0.1 mg.

\section{Results and Discussions}

Optical micrographs of the hot extruded matrix alloy and the developed hot extruded composite are shown in Fig.1. A uniform distribution of silicon carbide (SiC) within the matrix alloy and reduction in the size of silicon carbide particles in the hot extruded composite are observed. Majority of the silicon carbide particles posses sizes less than $10 \mu \mathrm{m}$. This drastic reduction in the silicon carbide particle size can be attributed to the high compressive stresses during hot extrusion. The black portions as indicated in Fig. 1 (b) represents the carbon fibre reinforcements in the matrix alloy A16061.

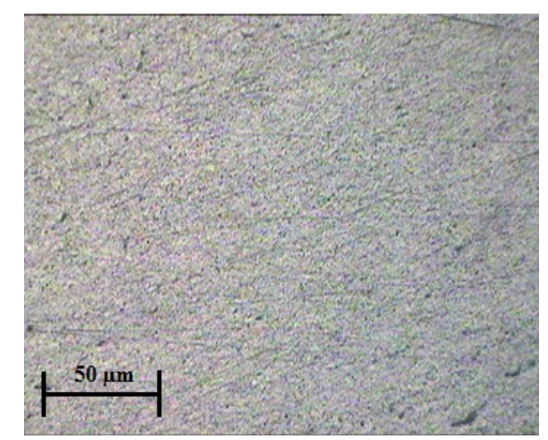

Fig. 1 (a)

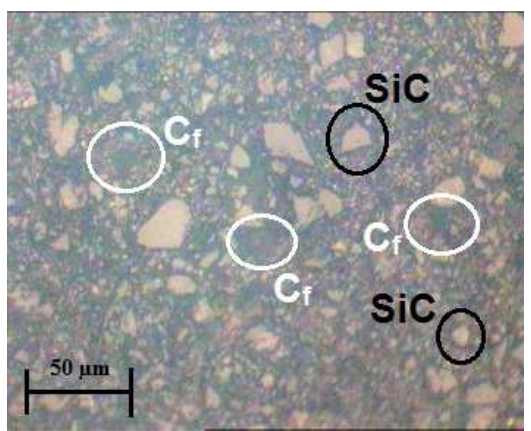

Fig. 1 (b)

Fig.1 Optical micrographs of (a) Hot Extruded Al6061 (b) Al6061-40Wt\%SiC-10Wt\% C composite.

The variation of micro hardness of hot extruded Al6061 alloy and Al6061-SiC-C $\mathrm{C}_{\mathrm{f}}$ hybrid composite are shown in Fig. 2. An improvement of $47 \%$ in the microhardness of the developed hybrid composite has been achieved. This can be attributed to high hardness of silicon carbide and also due to the thermal mismatch between the matrix alloy, silicon carbide and carbon fibre. The average coefficient of thermal expansion (CTE) of the Al6061 matrix alloy is $23 \mu \mathrm{m} / \mathrm{m}-{ }^{\circ} \mathrm{C}$, while that of cast Al6061- silicon carbide composite is in the range between $11.9-16.2 \mu \mathrm{m} / \mathrm{m}-{ }^{\circ} \mathrm{C}[15,16]$. Carbon fibres possess the least average CTE of value $0.5 \mu \mathrm{m} / \mathrm{m}-{ }^{\circ} \mathrm{C}$ [15]. This mismatch results in generation of high dislocation densities leading to improved hardness of the composite. 


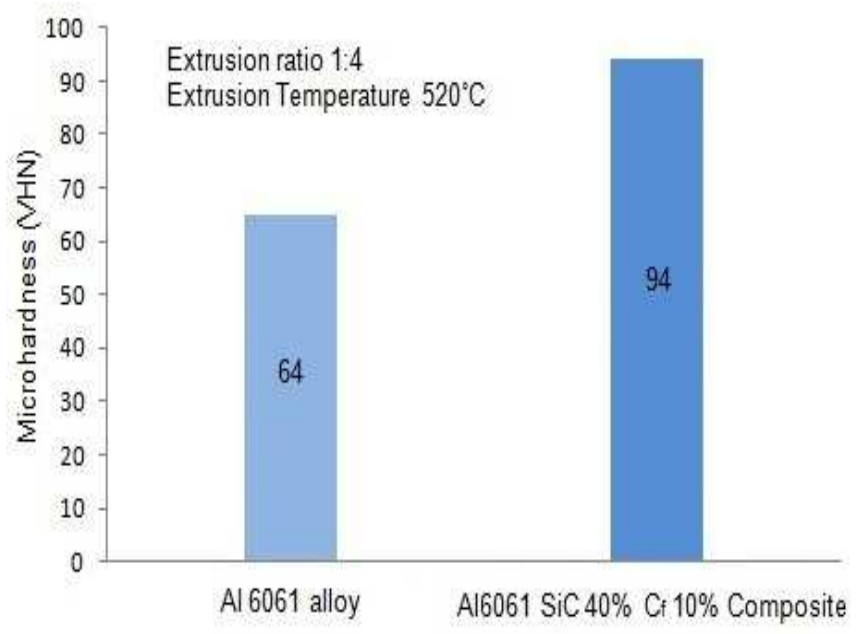

Fig.2 Variation of microhardness of Al 6061 matrix alloy and Al6061- 40Wt\% $\%$ SiC- $10 \mathrm{Wt} \% \mathrm{C}_{\mathrm{f}}$ composite.

The variation of weight loss due to solid particle erosion of the matrix alloy and developed composite with angle of impact is shown in Fig. 3. An average reduction of 30\% weight loss is observed for the developed composite when compared with the matrix alloy for all the studied angle of impacts. This demonstrates that the developed composite possesses excellent erosion wear resistance when compared with the matrix alloy. This can be attributed to improved hardness of the developed composites and good bond between the reinforcements and the matrix alloy as evidenced in Fig. 1 (b). It is observed that the maximum and minimum erosive wear loss for both the matrix alloy and the developed composite occurs at the impact angle of $60^{\circ}$ and $90^{\circ}$ respectively. This observation agrees with other researchers $[9,10]$. The maximum erosive wear loss can be attributed to the higher contact area between the erodent particle and the target leading to high deformation stresses resulting in severe surface degradation. Further, Scanning electron microscope (SEM) of the eroded worn surfaces will be discussed to enunciate the wear mechanism in the developed composite.

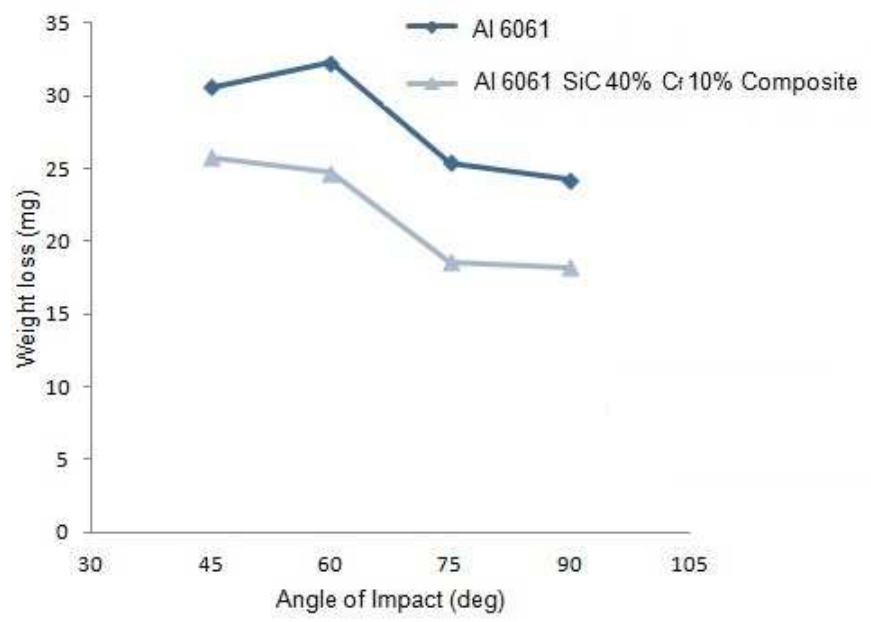

Fig.3 Variation of Weight loss of the Al 6061 matrix alloy and Al6061- 40Wt\% $\%$ SiC- $10 \mathrm{Wt} \% \mathrm{C}_{\mathrm{f}}$ composite for test duration of 30 minutes.

SEM of eroded surfaces of Al 6061 matrix alloy and Al 6061- 40wt $\%$ SiC- $10 \mathrm{wt} \% \mathrm{C}_{\mathrm{f}}$ composite are shown in Fig. 4. It is evident that the solid particle erosion results in microcracking within the matrix alloy and also lips formation as shown in Fig. 4 (a). This feature is due to lower hardness and high ductility of the matrix alloy. 


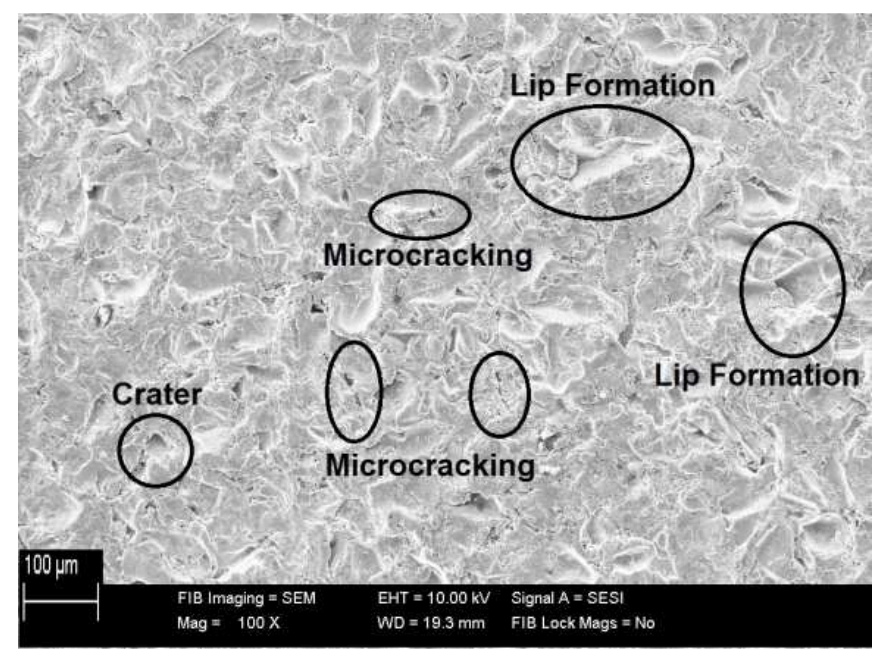

Fig. 4 (a)

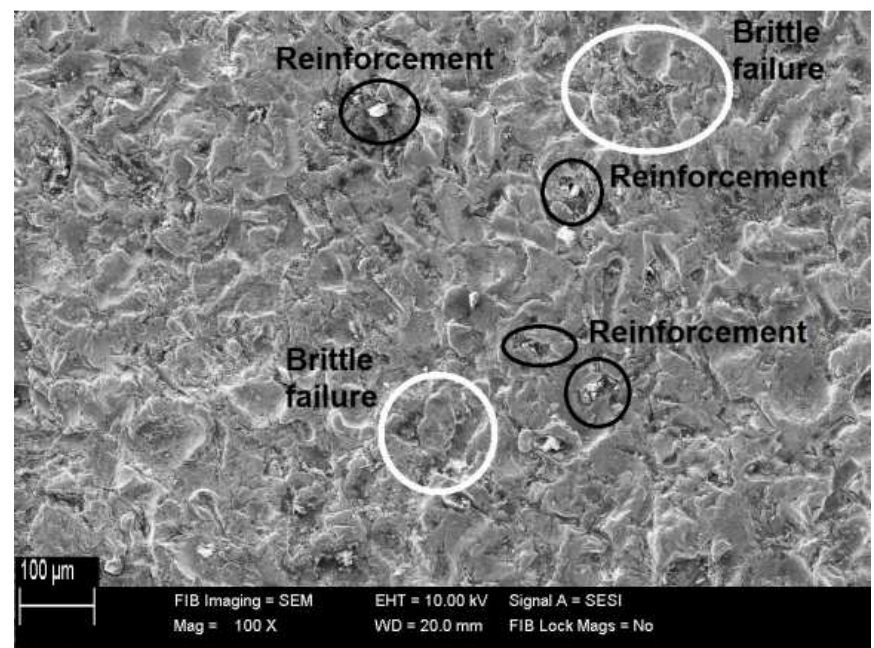

Fig. 4 (b)

Fig. 4 SEM image of $90^{\circ}$ eroded (a) Al6061 alloy (b) $\mathrm{Al} 6061-40 \mathrm{Wt} \% \mathrm{SiC}-10 \mathrm{Wt} \% \mathrm{C}_{\mathrm{f}}$ composite.

The eroded surfaces of the matrix alloy do exhibit craters at few locations indicating heavily strained regions on the alloy surface. Dominance of brittle failure of eroded surfaces is the characteristic features of the developed composite as shown in Fig. 4 (b). The micrographs clearly indicate absence of microcracking and lip formation. Further, damage to both the reinforcement's silicon carbide and carbon fibre are observed. 


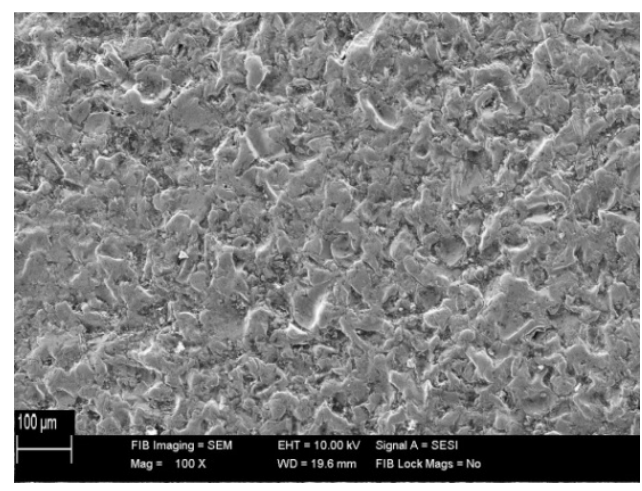

Fig. 5 (a)

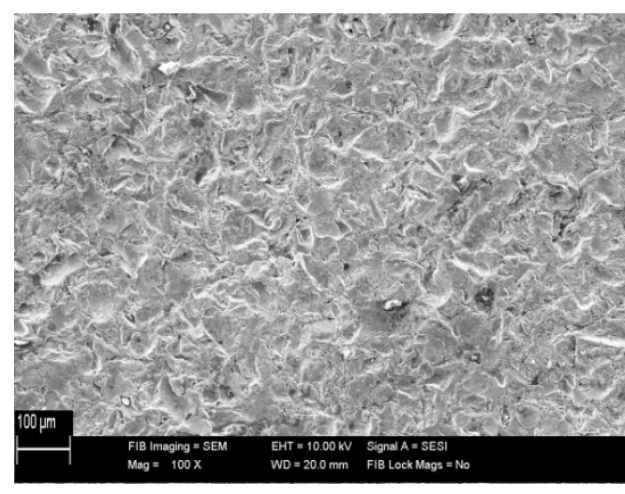

Fig. 5 (b)

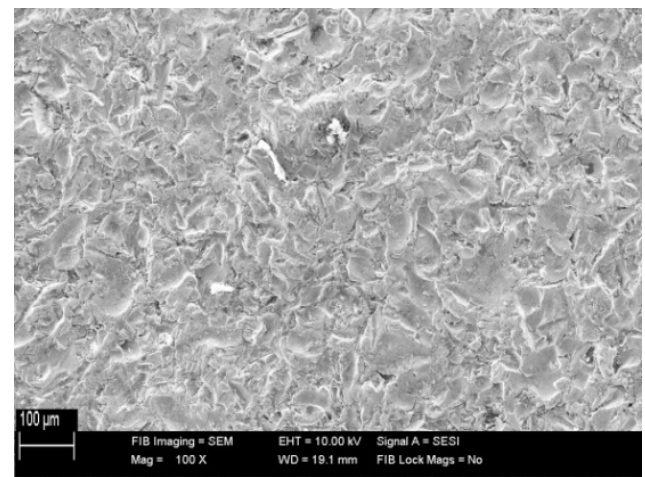

Fig. 5 (c)

Fig. 5 SEM image of (a) $75^{\circ}$ impact (b) $60^{\circ}$ impact (c) $45^{\circ}$ impact eroded Al6061- 40Wt $\%$ SiC$10 \mathrm{Wt} \% \mathrm{C}_{\mathrm{f}}$ composite.

SEM of eroded composite has confirmed microcracking, platelet, lip formation and small craters of indentation as various wear mechanisms. This is in accordance with other researchers [14]. The SEM images of Al6061- 40Wt $\% \mathrm{SiC}-10 \mathrm{Wt} \% \mathrm{C}_{\mathrm{f}}$ eroded composite shown in Fig. 5 reveals minimal material flow in the direction of impingement.

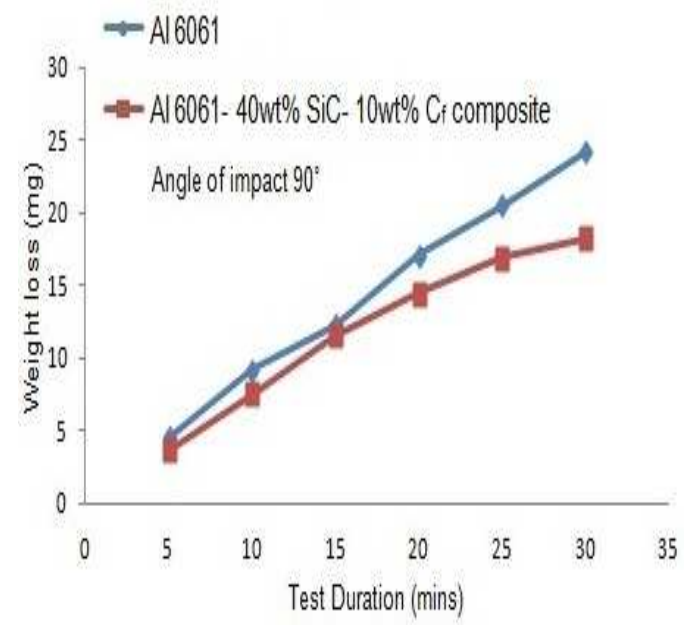

Fig. 6 (a) 


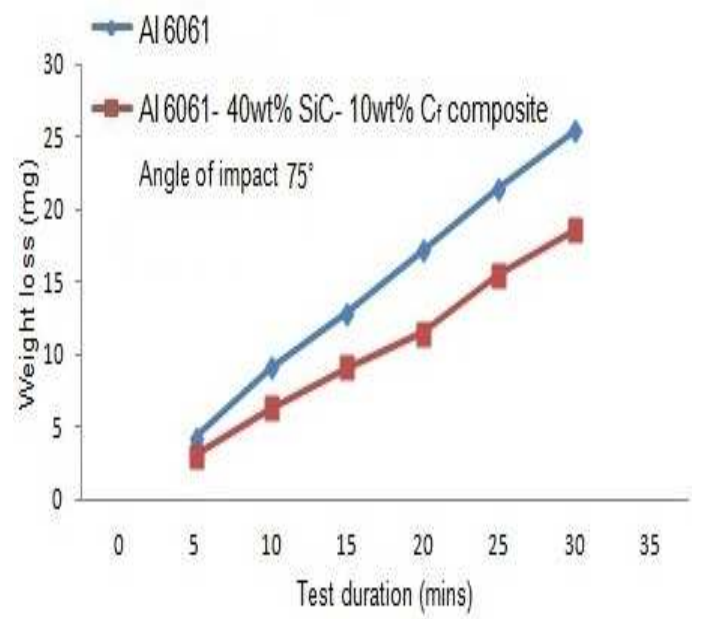

Fig. 6 (b)

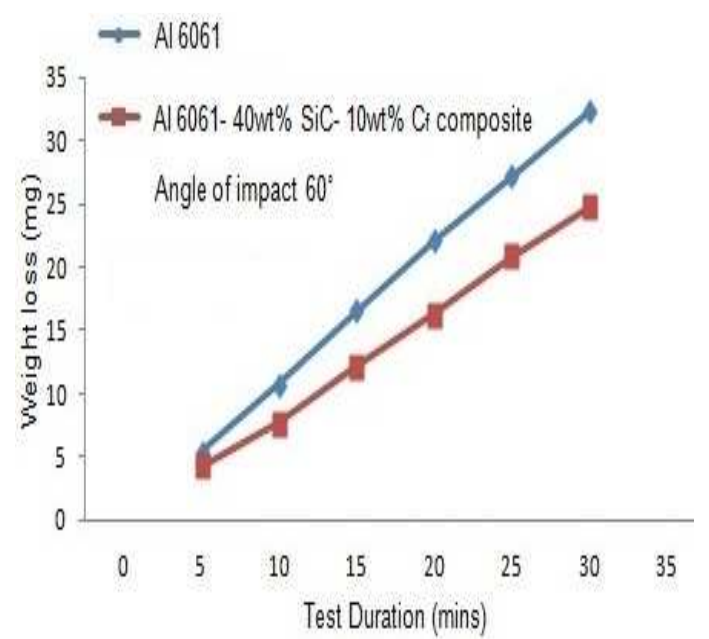

Fig. 6 (c)

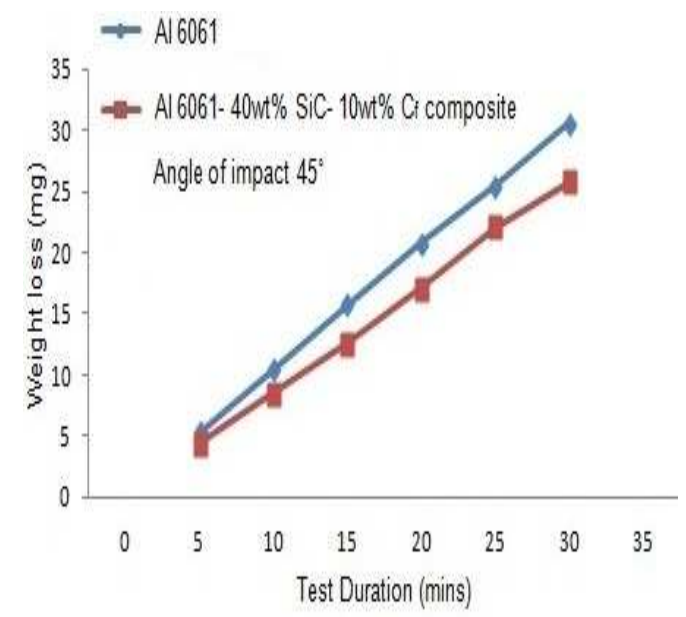

Fig. 6 (d)

Fig. 6 Variation of Weight loss with angle of impact (a) $90^{\circ}$ (b) $75^{\circ}$ (c) $60^{\circ}$ and (d) $45^{\circ}$ air jet eroded $\mathrm{Al} 6061$ matrix alloy and $\mathrm{Al} 6061-40 \mathrm{Wt} \% \mathrm{SiC}-10 \mathrm{Wt} \% \mathrm{C}_{\mathrm{f}}$ composite.

The variation in erosive weight loss of Al6061 alloy and Al6061- 40wt $\%$ SiC- $10 \mathrm{wt} \% \mathrm{C}_{\mathrm{f}}$ composite with test duration is shown in Fig. 6 for angles of impact of $90^{\circ}, 75^{\circ}, 60^{\circ}$ and $45^{\circ}$. A gradual increase in wear loss with increase in test duration is observed .Under all the test durations, the developed composites exhibited higher wear resistance when compared with matrix alloy. 


\section{Summary}

Al6061-SiC-Carbon fibre hybrid composite exhibit higher erosion wear resistance when compared with Al6061 matrix alloy. SEM of eroded surfaces of Al6061 alloy have confirmed microstructural features that are characteristics of ductile failure mode while SEM of Al6061- $40 \mathrm{Wt} \% \mathrm{SiC}-10 \mathrm{Wt} \%$ $\mathrm{C}_{\mathrm{f}}$ composite have exhibited brittle failure features.

Acknowledgments: The authors gratefully acknowledge the cooperation and support extended by Prof. D. Jawahar, CEO, PES Institutions, and Dr. K.N.B. Murthy, Principal, PESIT, Bangalore in carrying out this work.

\section{References}

[1]Ramesh.C.S, Harsha.R.Gudi, Nirupama Mohan and Adarsh.H, Development of innovative Al6061-SiC composite by hybrid technique. Editors- Proceedings of STLE Conference May 610, 2012, St. Louis, USA, 2012.

[2]C.S. Ramesh and Mir Safiulla, Wear behaviour of hot extruded Al6061 based composites, Wear Vol. 263, (2007) 629-635.

[3]C.S. Ramesh and T.B. Prasad, Dry sliding friction and wear behaviour of hypereutectic Al-SiCarbon fibre metal matrix composite, Tribology Vol. 1 No. 4, (2007) 197-202.

[4]C.S. Ramesh, R. Keshavamurthy, S. Pramod and Praveennath G. Koppad, Abrasive wear behavior of $\mathrm{Ni}-\mathrm{P}$ coated $\mathrm{Si}_{3} \mathrm{~N}_{4}$ reinforced Al6061 composites, Journal of Materials Processing Technology Vol. 211, (2011) 1423-1431.

[5]R.K. Uyyuru, M.K. Surappa, and S. Brusethaug, Tribological behavior of Al-Si-SiCp composites/automobile brake pad system under dry sliding conditions, Tribology International Vol. 40, (2007) 365-373.

[6]Ranjit Bauri and M.K. Surappa, Sliding wear behavior of Al-Li-SiCp composites, Wear Vol. 265, (2008) 1756-1766.

[7]Tamer Sinmazcelik, Sinan Fidan and Volkan Gunay, Residual mechanical properties of carbon/polyphenylenesulphide composites after solid particle erosion, Materials and Design Vol. 29, (2008) 1419-1426.

[8]S.S. Mahapatra and Amar Patnaik, Study on mechanical and erosion wear behavior of hybrid composites using Taguchi experimental design, Materials and Design Vol. 30, (2009) 27912801.

[9]Brian E. MacMillin, Christopher D. Roll and Paul Funkenbusch, Erosion and surface structure development of metal-diamond particulate composites, Wear Vol. 269, (2010) 875-883.

[10] R.J.K. Wood and A.J. Speyer, Erosion-corrosion of candidate HVOF aluminium-based marine coatings, Wear Vol. 256, (2004) 545-556.

[11] Z. Huang, Z.Z. Li and X. Yuan, The effect of reinforcing particles on the erosive wear behavior of particles reinforced silicone matrix composite coating, Wear Vol. 249, (2001) 10461050.

[12] A.P. Harsha and Avinash A. Thakre, Investigation on solid particle erosion behaviour of polyetherimide and its composites, Wear Vol.262, (2007) 807-818.

[13] S.S. Mahapatra, Amar Patnaik and Alok Satapathy, Taguchi method applied to parametric appraisal of erosion behaviour of GF-reinforced polyester composites, Wear Vol. 265, (2008) 214-222.

[14] A.P. Harsha and Deepak Kumar Bhaskar, Solid particle erosion behaviour of ferrous and non-ferrous materials and correlation of erosion data with erosion models, Materials and Design Vol. 29, (2008) 1745-1754.

[15] Information on http://www.performance-composites.com/carbonfibre/mechanicalproperties_1.asp

[16] Information on http://www.thermaltc.com/materials.html 